\title{
Haloperidol ameliorates androgen-induced behavioral deficits in developing male rats
}

\author{
Chunxiao Qi1,2,*, Xiaoming Ji1,*, Guoliang Zhang²,*, Yunxiao Kang1, Yuanxiang Huang³, Rui Cui², Shuangcheng Li², \\ Huixian Cui'2,4 and Geming Shi1,2,4 \\ 'Department of Neurobiology, Hebei Medical University, Shijiazhuang, People's Republic of China \\ 2Department of Human Anatomy, Hebei Medical University, Shijiazhuang, People's Republic of China \\ ${ }^{3}$ Grade 2015 Eight-year Clinical Medicine Program, School of Basic Medical Sciences, Hebei Medical University, Shijiazhuang, People's Republic of China \\ ${ }^{4}$ Neuroscience Research Center, Hebei Medical University, Shijiazhuang, People's Republic of China
}

Correspondence should be addressed to G Shi: shigeming@163.com

*(C Qi, X Ji and G Zhang contributed equally to this work)

\section{Abstract}

The purpose of present study was to infer the potential effects of testosterone increase in some male-based childhood-onset neuropsychiatric disorders, such as Tourette syndrome. Thus, the influence of early postnatal androgen exposure upon the neurobehaviors and its possible neural basis were investigated in the study. Male pup rats received consecutive 14-day testosterone propionate (TP) subcutaneous injection from postnatal day (PND) 7. The TP treatment produced the hyperactive motor behavior and grooming behavior as well as the increased levels of dopamine, tyrosine hydroxylase and dopamine transporter in the mesodopaminergic system and the elevated levels of serotonin in the nucleus accumbens, without affecting the levels of glutamate, $\gamma$-aminobutyric acid, norepinephrine and histamine in the caudate putamen and nucleus accumbens of PND21 and PND49 rats. Dopamine D2 receptor antagonist haloperidol was administered to the early postnatal TP-exposed PND21 and PND49 male rats $30 \mathrm{~min}$ prior to open field test. Haloperidol significantly ameliorated the motor behavioral and grooming behavioral defects induced by early postnatal TP exposure. The results demonstrated that early postnatal androgen exposure significantly disturbed the brain activity of developing male rats via enhancing the mesodopaminergic activity. It was suggested that abnormal increments of testosterone levels during the early postnatal development might be a potential risk factor for the incidence of some male-based childhood-onset neuropsychiatric disorders by affecting the mesodopaminergic system.

\author{
Key Words \\ - haloperidol \\ - testosterone propionate \\ - neurobehavior \\ - dopaminergic system \\ - male rats
}

Journal of Endocrinology (2018) 237, 193-205

\section{Introduction}

Sex differences in the incidence, onset or severity have been documented in the studies on childhood-onset neuropsychiatric disorders, such as Tourette syndrome (TS) (Sandyk et al. 1988). Male TS patients have a higher predominance, with the sex ratio of males to females reported ranging from around 3:1 to 10:1 (Freeman et al.
2000, Khalifa \& von Knorring 2003, Jin et al. 2005). Tourette syndrome has a distinctive natural history with onset of tics in childhood, common exacerbation of tics near the onset of puberty and frequent moderation or resolution of tics as TS patients enter adulthood (Bloch \& Leckman 2009). The increased testosterone is detected in 
an extremely severe TS boy (Zou et al. 2011). Anti-androgen treatment alleviates the symptoms of TS patients (Peterson et al. 1998, Bortolato et al. 2007, Muroni et al. 2011) and administration of exogenous androgens exacerbates tic symptom (Leckman \& Scahill 1990). The natural history, marked male predominance and symptom relief via antiandrogen treatment of TS suggest that the hyperandrogen environment during the early development might be involved in the regulation of the brain activity of male TS patients.

Brain activity depends on the balanced neurotransmissions. An imbalance in dopamine (DA) neurotransmissions leads to either hyperactive or hypoactive neuropsychiatric disorders (Mehler-Wex et al. 2006, Howes \& Kapur 2009, Leckman et al. 2010, Chen et al. 2013). Elevation of DA, as a driver of psychosis, induces schizophrenia (Howes \& Kapur 2009, Kegeles et al. 2010) and reduction of DA within the nigrostriatal pathway results in Parkinson disease (Mehler-Wex et al. 2006). The studies on TS patients show that dopaminergic (DAergic) dysfunction is implicated in the pathophysiology of TS (Steeves \& Fox 2008, Wong et al. 2008, Leckman et al. 2010). Increased dopamine transporter-binding sites and amphetamine-induced increased release of DA are detected in TS patients or postmortem (Singer et al. 1991, 2002, Albin et al. 2003, Wong et al. 2008). AntiDAergic agents reduce effectively tics (Scahill et al. 2006). The studies above demonstrate that the central DAergic activity is enhanced in TS patients.

Abnormal elevation in testosterone levels during the early postnatal development might account for a higher predominance and severity in some male-based childhood-onset neuropsychiatric disorder patients. Hyperandrogen environment in developing males might induce neurobehavioral deficits by altering the activity of central DAergic system, which might be retrieved by haloperidol (Hal) treatment. Haloperidol, a D2 receptor antagonist, is widely used for the treatment of schizophrenia, affective disorders and TS (Silay \& Jankovic 2005, Termine et al. 2013, Egolf \& Coffey 2014). It can control the tics and vocal utterances associated with TS (Tyler et al. 2017). Therefore, to infer the potential effects of testosterone increase in some male-based childhoodonset neuropsychiatric disorders, such as TS, the present study analyzed the alterations of neurobehaviors and neurotransmitters as well as the influence of Hal upon the neurobehavioral deficits in male rats affected with early postnatal androgen exposure.

\section{Materials and methods}

Animals

Pregnant Wistar rats were obtained from the Experimental Animal Center of Hebei Medical University during their first week of gestation and housed singly in an airconditioned room $\left(22 \pm 2^{\circ} \mathrm{C}\right)$ on a 12-h light-darkness cycle (lights on 06:00h). Food and water were available ad libitum. Pregnant females were monitored and the day of birth for pups was defined as postnatal day (PND) 0 . In order to avoid any cohort effects, male pup rats of the same litter were randomly assigned to different treatment groups. Six male and 3 female pups were kept in the same cage with a dam and weaned on PND21. After weaning, the male rats were housed with four rats per cage and the female rats were not used in the study. All of the experimental procedures followed the rules in the 'Guidelines for the Care and Use of Mammals in Neuroscience and Behavioral Research' and approved by the Committee of Ethics on Animal Experiments at Hebei Medical University.

\section{Experiment 1}

The purpose of Experiment 1 was to investigate the effects of early postnatal TP exposure on the neurobehaviors and neurochemicals of male rats. Twelve pregnant Wistar rats were used to collect 72 male pup rats. The male offspring were treated by the subcutaneous injection of TP $(0.5 \mathrm{mg}, 20 \mu \mathrm{L})$ once daily or sesame oil from PND7 to PND20 and were designated as TP group or control (C) group. Twelve rats in each group were killed at PND21, PND49 or PND168, which corresponded to 3-week (3 w) old, 7-week (7 w) old and 24-week (24 w) old, respectively. Liquid chromatography coupled with tandem mass spectrometry (LC-MS/MS) was used to measure the levels of DA, 3,4-dihydroxyphenylacetic acid (DOPAC), homovanillic acid (HVA), serotonin (5-HT), glutamate (Glu), $\gamma$-aminobutyric acid (GABA), norepinephrine (NE) and histamine (His) in the caudate putamen $(\mathrm{CPu})$ and nucleus accumbens (Acb). Based on the neurochemical results, real-time quantitative polymerase chain reaction (qPCR) and Western blot were used to detect the alterations of mRNA and protein levels of related markers in corresponding neural system. Furthermore, body weight, seminal vesicle and testis weights were documented when the rats were killed. 


\section{Experiment 2}

The aim of Experiment 2 was to analyze if haloperidol might ameliorate the neurobehavioral defects in early postnatal TP-treated male rats based on the results of Experiment 1. Haloperidol was dissolved in physiological saline (Sal) and given to experimental animals according to the following experimental design. Eighty-four male pup rats from 14 mother rats were used. As described in Experiment 1, they received the subcutaneous injection of TP or sesame oil and fell into TP group or $\mathrm{C}$ group. At PND21 or PND49, prior to the open field test, they were further divided into following groups: C-Sal, TP-Sal, C-0.02Hal, C-0.15Hal, TP-0.02Hal and TP-0.15Hal. In each group, 7 rats were used. They received Sal treatment or Hal injection $(0.02$ or $0.15 \mathrm{mg} / \mathrm{kg}$, i.p.) $30 \mathrm{~min}$ before the open field test at $1 \mathrm{~mL} / \mathrm{kg}$ body weight (Hidaka et al. 2010).

\section{Experiment 3}

The aim of Experiment 3 was to analyze the effects of Hal treatment concurrent with TP treatment on the neurobehaviors of developing male rats. PND21 and PND49 male rats were used. They were randomly divided into C, C-TP, C-Hal and Hal-TP groups. There were 7 rats in each group. Thirty minutes before the open field test, the rats in C-TP, C-Hal and Hal-TP groups received one injection of TP $(0.5 \mathrm{mg}$ and $20 \mu \mathrm{L})$, Hal $(0.15 \mathrm{mg} / \mathrm{kg})$ and Hal concurrent with TP treatment respectively. The rats in $\mathrm{C}$ group received corresponding vehicle treatment.

\section{Open field test}

Open field test was performed according to the procedures used in our previous study (Zhang et al. 2011). Prior to the behavioral test, all the rats for open field test were tail-marked and handled for 5 days and received 2-day accustomization to the open field apparatus for $5 \mathrm{~min}$ and $15 \mathrm{~min}$ respectively. The test was performed between 08:00 $\mathrm{h}$ and 11:00 h. Each rat was placed in the center of an open field chamber $(100 \times 100 \times 40 \mathrm{~cm})$ under a luminance of 20 lux. Fifteen-minute open field behavior of each rat was recorded for later analysis. Two types of behavioral patterns, motor behavior and grooming behavior, were analyzed in the study.

\section{Sample preparation}

Following open field test, 12 rats in each group of Experiment 1 were killed by decapitation. The brains were removed quickly. The tissue block containing the substantia nigra (SN), ventral tegmental area (VTA), $\mathrm{CPu}$ or Acb was dissected according to The Rat Brain in Stereotaxic Coordinates (Paxinos \& Watson 1997) on an ice cold plate using a scalpel for ophthalmic surgery and stereomicroscope. The tissue blocks were processed for LC-MS/MS, qPCR or Western blot analysis based on the study purposes.

\section{LC-MS/MS assay}

The tissue block of the $\mathrm{CPu}$ or Acb was weighed and homogenized in $80 \%$ acetonitrile containing $0.1 \%$ formic acid $(5 \mu \mathrm{L} / \mathrm{mg})$. The homogenates were centrifuged at $21,100 \boldsymbol{g}$ and $4^{\circ} \mathrm{C}$ for $10 \mathrm{~min}$. The supernatants were collected and stored at $-80^{\circ} \mathrm{C}$. Dopamine, DOPAC, HVA, 5-HT, Glu, GABA, NE and His were determined by LC-MS/MS. The LC separation was performed on an Agilent 1200 LC system (Agilent) using a Synergi Fusion-RP C18 column $(50 \times 3.0 \mathrm{~mm}, 4 \mu \mathrm{m})$ provided by Phenomenex. MS/MS detection was carried out using a 3200 QTRAP LC-MS/MS system (Applied Biosystems). The multiple-reaction monitoring mode was used for the quantification.

\section{qPCR analysis}

Total RNA $(2 \mu \mathrm{g})$ from the SN or VTA tissue block was subjected to reverse transcription using random primer to obtain the first-strand cDNA template. qPCR was performed with $0.8-\mu \mathrm{L}$ cDNA (diluted $1: 10$ ), $2-\mu \mathrm{L}$ specific primers and 2X GoTaq Green Master Mix (Promega) with a final volume of $20 \mu \mathrm{L}$. PCR was performed as follows: an initial cycle at $95^{\circ} \mathrm{C}$ for $10 \mathrm{~min}$, followed by 40 cycles at $95^{\circ} \mathrm{C}$ for $15 \mathrm{~s}, 58^{\circ} \mathrm{C}$ for $20 \mathrm{~s}$ and $72^{\circ} \mathrm{C}$ for $27 \mathrm{~s}$. The products were then analyzed by melting curve to confirm the specificity of amplification. The expression of tyrosine hydroxylase (TH) and dopamine transporter (DAT) genes was analyzed using glyceraldehyde-3-phosphate dehydrogenase (GAPDH) as an internal control. For all samples, qPCR was performed in triplicate and the data were averaged. The relative quantification was calculated using the $2^{-\Delta \Delta C t}$ method. The sets of primers were as follows: Th (5'-GCTTCTCTGACCAGGTGTATCG-3' and $5^{\prime}$-GCAATCTCTTCCGCTGTGTAT-3'), Dat (5'-ACTCTGTGAGGCATCTGTGTG-3' and 5'-TGTAACTGGAGAAGGCAATCAG-3'), Gapdh (5'-TGAACGGGAAGCTCACTG-3' and 5'-GCTTCACCACCTTCTTGATG-3'). http://joe.endocrinology-journals.org
https://doi.org/10.1530/JOE-17-0642
(C) 2018 Society for Endocrinology Published by Bioscientifica Ltd.
Printed in Great Britain 


\section{Western blot analysis}

The $\mathrm{CPu}$ or Acb tissue blocks for detection of $\mathrm{TH}$ and DAT protein levels were homogenized in radioimmunoprecipitation assay (RIPA) buffer containing 1\% Triton X-100, 0.1\% SDS, 0.5\% sodium deoxycholate and protease inhibitors $(100-\mu \mathrm{g} / \mathrm{mL}$ phenylmethanesulfonyl fluoride, $30-\mu \mathrm{g} / \mathrm{mL}$ aprotinin and $1-\mathrm{mM}$ sodium orthovanadate), and then sonicated for $4 \times 10 \mathrm{~s}$. After centrifugation at $12,000 \boldsymbol{g}$ for $20 \mathrm{~min}$ at $4^{\circ} \mathrm{C}$, the supernatant was collected and centrifuged again as described earlier. The resulting final supernatant was stored at $-80^{\circ} \mathrm{C}$ until use. Samples from the $\mathrm{CPu}(50 \mu \mathrm{g})$ or Acb $(50 \mu \mathrm{g})$ were diluted with $2 \times$ sample buffer $(50-\mathrm{mM}$ Tris, $\mathrm{pH}$ 6.8, 2\% SDS, 10\% glycerol, 0.1\% bromophenol blue, and 5\% $\beta$-mercaptoethanol) and heated for $5 \mathrm{~min}$ at $95^{\circ} \mathrm{C}$ before sodium dodecyl sulfate polyacrylamide gel electrophoresis (SDS-PAGE) on a $10 \%$ gel, and subsequently transferred to a polyvinylidene fluoride (PVDF) membrane (Millipore). The membrane was incubated for $2 \mathrm{~h}$ with $5 \%$ nonfat dry milk in Tris-buffered saline (TBS) containing 0.05\% Tween 20 (TBST) (20-mM Tris-Cl, $137-\mathrm{mM} \mathrm{NaCl}, 0.1 \%$ Tween 20, pH 7.6) at room temperature. The membrane was rinsed three times with TBST and then incubated overnight with mouse anti-TH monoclonal antibody (Sigma, T2928, 1:10,000) or rabbit anti-DAT polyclonal antibody (Millipore; AB2231, 1:4000) at $4^{\circ} \mathrm{C}$ based on the experimental aims. After washing thrice, the membrane was incubated for $1 \mathrm{~h}$ in IRDye 800-conjugated goat anti-mouse second antibody (1:3000, Rockland, Gilbertsville, PA, USA) or goat anti-rabbit second antibody (1:3000, Rockland) at room temperature. The relative density of bands was analyzed on an Odyssey infrared scanner (LI-COR Biosciences, Lincoln, NE, USA). Following stripping, each PVDF membrane was subsequently immunoblotted with mouse anti- $\beta$ actin monoclonal antibody (Santa Cruz Biotechnology; sc-47778). The densitometry values of TH, or DAT were normalized with respect to those of $\beta$-actin, which were the endogenous control. For all samples, Western blots were performed in triplicate and the data were averaged.

\section{Hormone assays}

The trunk blood was collected when the rats were killed by decapitation in Experiment 1 . The levels of serum testosterone were determined by radioimmunoassay using radioimmunoassay kit (Cat. PID RG4, Tianjin Nine Tripods Medical and Bioengineering Co. Ltd, China).

\section{Statistical analysis}

All data were presented as mean \pm s.D. Between-group differences in Experiment 1 were evaluated using independent sample $t$-tests. The data in Experiment 2 and Experiment 3 were analyzed by the tests of normality (Kolmogorov-Smirnov test) and homogeneity variance (Levene's test). Then, parametric test was performed by one-way ANOVA followed by a Student-NewmanKeuls (SNK) post hoc test for multiple comparisons or nonparametric statistics were done by Kruskal-Wallis test followed by Mann-Whitney $U$ test for post hoc analysis between groups. A criterion for statistical confidence of $P<0.05$ was used.

\section{Results}

Body weight as well as seminal vesicle and testis weights

There was no significant difference in the body weight of rats between $\mathrm{C}$ group and TP group at 3-, 7- or 24-week old. In addition to the body weight, the seminal vesicle and testis weights were also analyzed between $\mathrm{C}$ group and $\mathrm{TP}$ group at the end of Experiment 1 to confirm peripheral effects of androgen during early postnatal TP treatment at the dose of $0.5 \mathrm{mg} /$ day. The TP exposure increased the seminal vesicle weight of rats at 3 weeks old $(P<0.01)$ and reduced the testis weight of rats at 3 weeks and 7 weeks old $(P<0.01)$. There was no significant difference in the testis weight and seminal vesicle weight of rats between $C$ group and TP group at 24 week old (Table 1 ).

\section{Serum testosterone levels}

Consecutive 14-day TP exposure to PND7 male rats resulted in the high levels of serum testosterone in the rats at 3 weeks old $(P<0.01)$ and the low levels of serum testosterone in the rats at 7 weeks old $(P<0.01)$. There was no significant difference in the serum testosterone levels of rats between $\mathrm{C}$ group and TP group at 24 weeks old (Table 1).

\section{Motor behavior and grooming behavior}

The effects of early postnatal TP exposure on brain activity were investigated by analyzing the altered parameters of motor behavior and grooming behavior, which included vertical activity, horizontal activity and total path length 
Table 1 Effects of early postnatal TP exposure on body weight as well as seminal vesicle and testis weights and serum testosterone of male rats $(n=12)$.

\begin{tabular}{|c|c|c|}
\hline & C & TP \\
\hline \multicolumn{3}{|l|}{3 week old } \\
\hline Body weight (g) & $47.4 \pm 7.0$ & $49.0 \pm 4.0$ \\
\hline Seminal vesicle weight (g) & $0.009 \pm 0.001$ & $0.097 \pm 0.011 *$ \\
\hline Testis weight (g) & $0.11 \pm 0.02$ & $0.08 \pm 0.01 *$ \\
\hline Testosterone (ng/mL) & $1.26 \pm 0.22$ & $55.87 \pm 10.26$ * \\
\hline \multicolumn{3}{|l|}{7 week old } \\
\hline Body weight (g) & $193.3 \pm 22.3$ & $184.6 \pm 29.6$ \\
\hline Seminal vesicle weight $(\mathrm{g})$ & $0.14 \pm 0.06$ & $0.13 \pm 0.03$ \\
\hline Testis weight (g) & $1.01 \pm 0.08$ & $0.76 \pm 0.09 *$ \\
\hline Testosterone (ng/mL) & $3.16 \pm 0.58$ & $1.47 \pm 0.34^{*}$ \\
\hline \multicolumn{3}{|l|}{24 week old } \\
\hline Body weight (g) & $439.7 \pm 27.0$ & $421.9 \pm 33.6$ \\
\hline Seminal vesicle weight $(\mathrm{g})$ & $1.06 \pm 0.15$ & $0.97 \pm 0.14$ \\
\hline Testis weight $(\mathrm{g})$ & $1.40 \pm 0.11$ & $1.37 \pm 0.12$ \\
\hline Testosterone (ng/mL) & $4.26 \pm 0.65$ & $4.12 \pm 0.77$ \\
\hline
\end{tabular}

for motor behavior, as well as the latency, number and duration of grooming for grooming behavior (Zhang et al. 2011). Except for the latency of grooming, all other behavioral parameters were elevated in the rats of TP group compared with the rats of $\mathrm{C}$ group at 3 weeks old (Figs $1 \mathrm{~A}, \mathrm{~B}$ and $\mathrm{C}$ and $2 \mathrm{~B}$ and $\mathrm{C}, P<0.01$ ) or at 7 weeks old (Figs $1 \mathrm{D}, \mathrm{E}$ and $\mathrm{F}$ and $2 \mathrm{E}$ and F. $P<0.01$ ). There was no significant difference in behavioral parameters of the rats between TP group and C group at 24 weeks old (Figs 1G, $\mathrm{H}$ and $\mathrm{I}$ and $2 \mathrm{G}, \mathrm{H}$ and $\mathrm{I})$.

\section{Alterations of neurochemical levels}

The changes of neurochemical levels were analyzed in the $\mathrm{CPu}$ and Acb of rats affected with early postnatal TP exposure. Both brain regions are related to the regulation of motor behavior and grooming behavior. There was no significant difference in the levels of Glu, GABA, NE and His in the $\mathrm{CPu}$ and Acb of rats between TP group and $\mathrm{C}$ group at 3 weeks, 7 weeks and 24 weeks old (Table 2). The significant increments of $\mathrm{DA}$ levels in the $\mathrm{CPu}$ and $\mathrm{Acb}$ ( 3 weeks old, $\mathrm{CPu}: P<0.05$; Acb: $P<0.01 ; 7$ weeks old, $\mathrm{CPu}$ : $P<0.05$; Acb: $P<0.01)$, HVA in the $\mathrm{CPu}$ ( 7 weeks old: $P<0.01)$ and 5-HT in the Acb (3 weeks old: $P<0.05 ; 7$ weeks old: $P<0.01)$, as well as the reduction of the DOPAC+HVA/DA ratio in the Acb (3 weeks old: $P<0.01$ ) were found in the rats of TP group, as compared to $\mathrm{C}$ group (Table 2). There was no significant difference in the levels of DA, DOPAC, HVA and 5-HT, or in the DOPAC+HVA/DA ratio in the $\mathrm{CPu}$ and $\mathrm{Acb}$ of rats between TP group and $\mathrm{C}$ group at 24 weeks old (Table 2 ).

\section{TH and DAT expression}

Based on the revealed alterations of neurochemical levels in the $\mathrm{CPu}$ and $\mathrm{Acb}$ of the rats between TP group and $\mathrm{C}$ group, the mesoDAergic system became our main concern and their markers, TH and DAT, were further studied. Elevated TH and DAT at mRNA levels in the SN and VTA (Fig. 3A, B, D and E, $P<0.01$ ) as well as at protein levels in the $\mathrm{CPu}$ and Acb (Fig. 3G, H, I, J, K and L, $P<0.01$ ) were
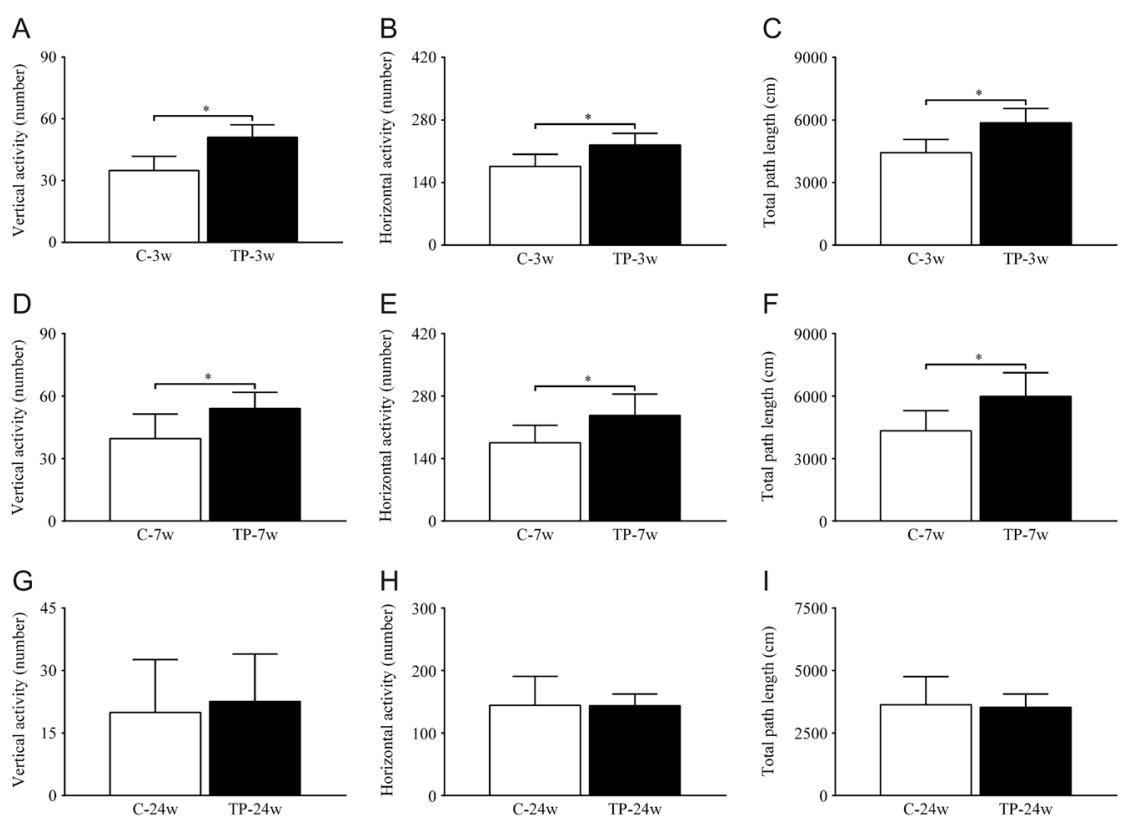

\section{Figure 1}

Effects of early postnatal androgen exposure on motor behavior. Early postnatal TP exposure increased the vertical activity and horizontal activity as well as total path length of PND21 (A, $B$ and C) and PND49 (D, E and F) male rats. (G, H and $I)=P N D 168$. The results were expressed as mean \pm S.D. $(n=12)$. * $P<0.01$. 
A

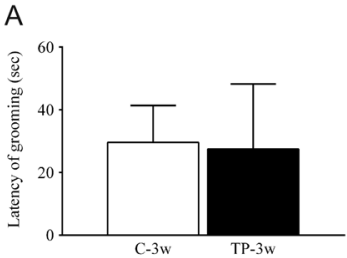

$\mathrm{D}$

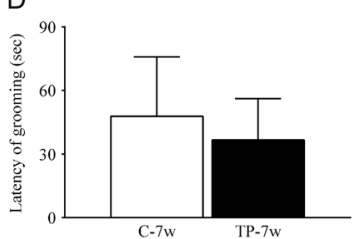

G

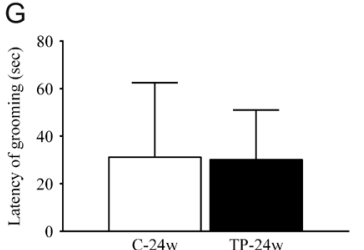

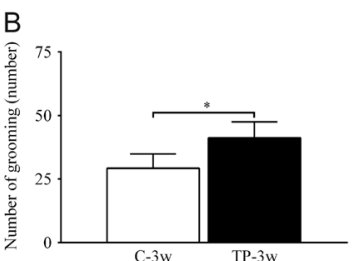
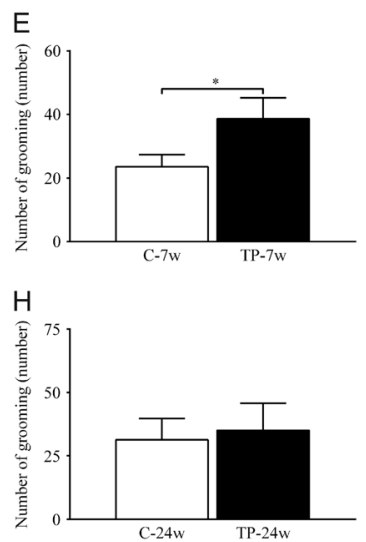

C

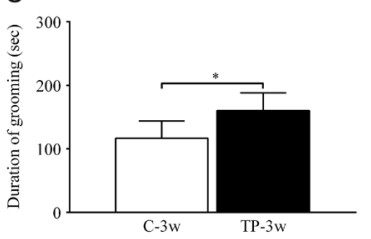

$\mathrm{F}$
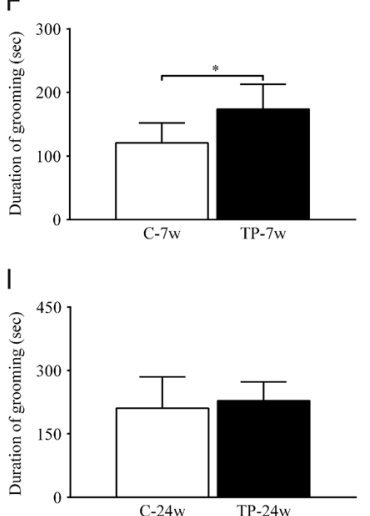

Figure 2

Effects of early postnatal androgen exposure on grooming behavior. Early postnatal TP exposure increased the number of grooming and duration of grooming of PND21 (B and C) and PND49 (E and F) male rats. There was no significant difference of early postnatal androgen exposure on the latency of grooming of PND21 (A) and PND49 (D) male rats. $(\mathrm{G}, \mathrm{H}$ and $\mathrm{I})=$ PND168. The results were expressed as mean \pm s.D. $(n=12)$. $* P<0.01$. observed in the rats of TP group at 3 weeks and 7 weeks old. There was no significant difference in TH and DAT expression of rats between TP group and $\mathrm{C}$ group at 24 weeks old.

\section{Effects of Hal on motor behavior and grooming behavior}

In Experiment 2, group differences among C-Sal, TP-Sal, C-0.02Hal, C-0.15Hal, TP-0.02Hal and TP-0.15Hal were observed in the behavioral parameters of motor behavior (Figs $4 \mathrm{~A}, \mathrm{~B}$ and $\mathrm{C}$ and $5 \mathrm{~A}, \mathrm{~B}$ and $\mathrm{C}, \mathrm{P}<0.01$ ) and grooming behavior (Figs $4 \mathrm{E}$ and $\mathrm{F}$ and $5 \mathrm{E}$ and $\mathrm{F}, P<0.01$ ) at 3 -week and 7 -week old. For motor behavior, the post hoc test showed the significant increments of behavioral parameters in TP-Sal (3-week old, vertical activity: $P<0.05$, horizontal activity and total path length: $P<0.01$; 7-week old, $P<0.01)$ and the marked decrements of them in C-0.15Hal (3-week and 7-week old, $P<0.01$ ) compared with C-Sal. The rats in TP-0.15Hal demonstrated the reduced levels of behavioral parameters compared with TP-Sal (3-week old, vertical activity: $P<0.01$, horizontal activity: $P<0.05$, total path length: $P<0.01$; 7 -week old, $P<0.01$ ) (Figs $4 \mathrm{~A}, \mathrm{~B}$ and $\mathrm{C}$ and $5 \mathrm{~A}, \mathrm{~B}$ and $\mathrm{C}$ ). For the grooming behavior, post hoc test revealed the more number and longer duration of grooming in TP-Sal (3-week old, number of grooming: $P<0.01$, duration of grooming: $P<0.05$; 7 -week old, $P<0.01$ ), as well as the less number and shorter duration in C-0.15Hal (3-week and 7-week old, number of grooming: $P<0.05$; duration of grooming: $P<0.01)$ than that in
C-Sal. Compared with TP-Sal, the number and duration of grooming significantly reduced in TP-0.15Hal (3-week old, number of grooming: $P<0.01$, duration of grooming: $P<0.05$; 7-week old, $P<0.01$ ) (Figs $4 \mathrm{E}$ and $\mathrm{F}$ and $5 \mathrm{E}$ and F). There was no significant difference in motor behavior and grooming behavior between C-Sal and TP-0.15Hal at 3-week and 7-week old (Figs 4 and 5).

In Experiment 3, significant reduction of motor behavior and grooming behavior was found in the rats of $\mathrm{C}-\mathrm{Hal}$ and Hal-TP compared with the rats of $\mathrm{C}$ and C-TP at PND21 (Fig. 4, $P<0.01$ ) and PND49 (Fig. 5, $P<0.01$ ). There was no significant difference in motor behavior and grooming behavior between $\mathrm{C}$ and C-TP, as well as C-Hal and Hal-TP (Figs 4 and 5).

\section{Discussion}

The present study showed that consecutive 14-day TP exposure to PND7 male rats induced the hyperactive motor behavior and grooming behavior, the increments of DA levels as well as the upregulation of TH and DAT expression at PND21 and PND49. Administration of Hal markedly ameliorated the early postnatal TP exposureinduced behavioral defects in PND21 and PND49 male rats. The results demonstrated that early postnatal androgen exposure disturbed the brain activity of developing male rats via enhancing the mesoDAergic activity. It was suggested that the abnormal increments of testosterone levels during the early postnatal development might be a 
Table 2 Neurochemical alterations in the CPu and Acb of male rats induced by early postnatal TP exposure ( $n=12, \mathrm{ng} / \mathrm{g})$.

\begin{tabular}{|c|c|c|c|c|}
\hline & \multicolumn{2}{|c|}{ CPu } & \multicolumn{2}{|c|}{ Acb } \\
\hline & C & TP & C & TP \\
\hline \multicolumn{5}{|l|}{3 week old } \\
\hline DA & $714.1 \pm 154.4$ & $864.4 \pm 111.7^{*}$ & $149.2 \pm 63.0$ & $418.5 \pm 54.1$ ** \\
\hline DOPAC & $1889.0 \pm 581.9$ & $2255.3 \pm 634.8$ & $1348.1 \pm 294.5$ & $1543.6 \pm 303.8$ \\
\hline HVA & $905.8 \pm 225.0$ & $1093.4 \pm 299.6$ & $909.9 \pm 186.2$ & $1013.9 \pm 191.7$ \\
\hline DOPAC+HVA/DA & $4.0 \pm 0.9$ & $3.9 \pm 1.2$ & $17.7 \pm 7.5$ & $6.2 \pm 1.3 * *$ \\
\hline $5-\mathrm{HT}$ & $90.8 \pm 22.8$ & $95.0 \pm 16.3$ & $80.2 \pm 16.2$ & $99.7 \pm 19.1$ * \\
\hline 5-HIAA & $686.2 \pm 160.6$ & $689.0 \pm 94.2$ & $618.4 \pm 148.4$ & $690.7 \pm 209.2$ \\
\hline NE & $3155.5 \pm 553.8$ & $3413.8 \pm 361.2$ & $2700.2 \pm 531.5$ & $2798.8 \pm 347.6$ \\
\hline GABA & $44768.4 \pm 11647.5$ & $50976.4 \pm 6041.7$ & $81944.2 \pm 17609.9$ & $82341.5 \pm 15701.8$ \\
\hline His & $633.1 \pm 124.5$ & $715.6 \pm 99.1$ & $687.0 \pm 117.1$ & $730.8 \pm 103.9$ \\
\hline Glu & $34410.4 \pm 6813.6$ & $38226.6 \pm 4955.5$ & $28252.4 \pm 9664.4$ & $26323.9 \pm 5796.2$ \\
\hline \multicolumn{5}{|l|}{7 week old } \\
\hline DA & $1417.3 \pm 196.6$ & $1686.5 \pm 326.3 *$ & $761.7 \pm 164.8$ & $942.7 \pm 99.9 * *$ \\
\hline DOPAC & $2059.3 \pm 722.7$ & $2434.8 \pm 752.0$ & $1309.0 \pm 256.8$ & $1599.3 \pm 434.6$ \\
\hline HVA & $539.5 \pm 153.9$ & $719.1 \pm 135.3 * *$ & $372.5 \pm 74.3$ & $442.8 \pm 126.0$ \\
\hline DOPAC+HVA/DA & $1.9 \pm 0.5$ & $1.9 \pm 0.3$ & $2.3 \pm 0.6$ & $2.2 \pm 0.6$ \\
\hline $5-\mathrm{HT}$ & $61.0 \pm 11.4$ & $70.0 \pm 13.2$ & $111.2 \pm 18.3$ & $146.7 \pm 19.9 * *$ \\
\hline 5-HIAA & $373.7 \pm 110.5$ & $415.2 \pm 80.7$ & $446.8 \pm 57.1$ & $484.1 \pm 97.1$ \\
\hline NE & $4646.0 \pm 601.4$ & $5099.3 \pm 744.7$ & $4042.2 \pm 567.4$ & $4137.1 \pm 642.7$ \\
\hline GABA & $33390.2 \pm 9343.5$ & $39635.6 \pm 9181.9$ & $78998.8 \pm 17192.7$ & $81361.0 \pm 13677.0$ \\
\hline His & $444.7 \pm 83.1$ & $511.4 \pm 100.4$ & $541.1 \pm 85.4$ & $581.1 \pm 121.7$ \\
\hline Glu & $40184.3 \pm 4326.0$ & $43601.8 \pm 5825.3$ & $32287.1 \pm 8031.8$ & $30383.3 \pm 6718.2$ \\
\hline \multicolumn{5}{|l|}{24 week old } \\
\hline DA & $901.7 \pm 68.8$ & $825.9 \pm 165.7$ & $85.0 \pm 19.2$ & $79.6 \pm 12.3$ \\
\hline DOPAC & $6673.0 \pm 1437.8$ & $6877.7 \pm 1689.8$ & $3195.5 \pm 524.4$ & $3013.9 \pm 902.1$ \\
\hline HVA & $1626.0 \pm 490.2$ & $1740.8 \pm 323.6$ & $1368.1 \pm 203.8$ & $1261.0 \pm 242.3$ \\
\hline DOPAC+HVA/DA & $9.2 \pm 2.0$ & $10.7 \pm 2.8$ & $56.5 \pm 14.7$ & $56.0 \pm 20.9$ \\
\hline $5-\mathrm{HT}$ & $834.7 \pm 56.4$ & $751.5 \pm 166.7$ & $397.2 \pm 68.1$ & $384.8 \pm 71.5$ \\
\hline 5-HIAA & $2848.7 \pm 493.9$ & $2904.0 \pm 443.8$ & $2492.5 \pm 583.8$ & $2382.2 \pm 562.1$ \\
\hline $\mathrm{NE}$ & $4480.5 \pm 431.4$ & $4767.0 \pm 534.1$ & $4210.0 \pm 543.0$ & $4221.5 \pm 574.1$ \\
\hline GABA & $38660.1 \pm 7119.6$ & $38858.8 \pm 6023.8$ & $94048.5 \pm 16105.7$ & $96960.4 \pm 15728.6$ \\
\hline $\mathrm{His}$ & $562.7 \pm 83.6$ & $600.7 \pm 98.0$ & $698.4 \pm 92.3$ & $692.9 \pm 133.2$ \\
\hline Glu & $44241.3 \pm 4550.6$ & $47241.4 \pm 5379.0$ & $35383.2 \pm 8482.2$ & $34914.3 \pm 7088.2$ \\
\hline
\end{tabular}

potential risk factor for the incidence of some male-based childhood-onset neuropsychiatric disorders by affecting the mesoDAergic system.

Testosterone produced by the testes regulates brain activity including cognitive, motor and motivational behaviors (Adler et al. 1999, Frye et al. 2008, Zhang et al. 2011, Celec et al. 2015). Gonadectomy decreased the ambulations of adult male rats in the open field (Adler et al. 1999, Zhang et al. 2011). Supplementation of TP to castrated rats recovered the reduced ambulation activity (Adler et al. 1999, Zhang et al. 2011) in the open field. Administration of testosterone to aged intact male animals elevates motor behavior (Frye et al. 2008, Cui et al. 2012). In the present study, we found that the motor behavior and grooming behavior of developing male rats were able to be manipulated via early postnatal testosterone exposure. The exposure of excessive testosterone during the early postnatal development produced the motor behavioral and grooming behavioral defects of PND21 and PND49 male rats. The increments of motor behavioral and grooming behavioral parameters were detected among them, which indicated the alteration of the brain function of PND21 and PND49 male rats to some extent.

Brain function is based on a balance of neurotransmissions (Steeves \& Fox 2008, Wong et al. 2008, Hidaka et al. 2010, Leckman et al. 2010). Abnormality in the neurotransmitter levels of the brain induces neurological or psychotic disorders, such as schizophrenia, Huntington's disease, Parkinson disease and TS (MehlerWex et al. 2006, Howes \& Kapur 2009, Kegeles et al. 2010, Leckman et al. 2010, Chen et al. 2013). Changes in brain DA content contribute to abnormal movements and cognitive deficits in Huntington's disease (Chen et al. 2013) and in Parkinson disease (Mehler-Wex et al. 2006). In the present study, among the neurochemicals detected by LC-MS/ MS assay, the main findings were the increments of DA 
A

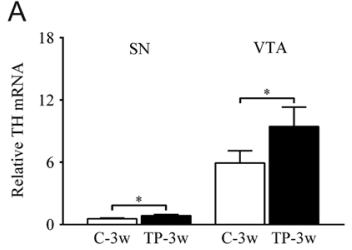

D

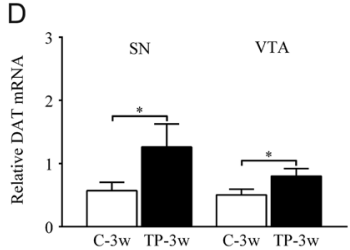

G
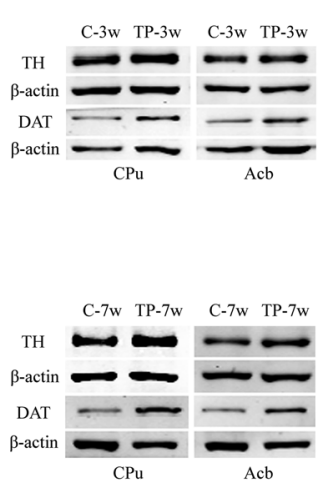

M

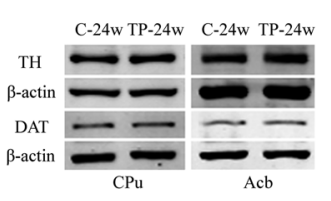

B
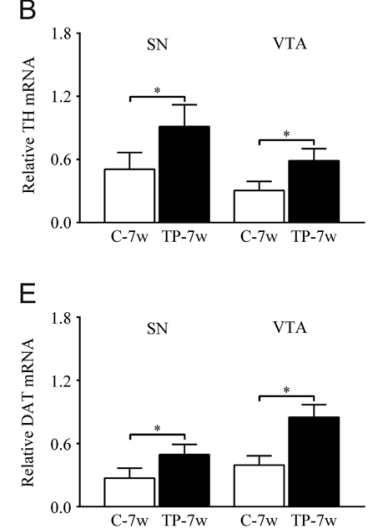

$\mathrm{H}$

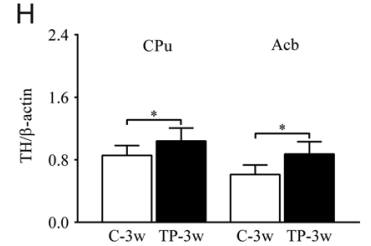

$\mathrm{K}$

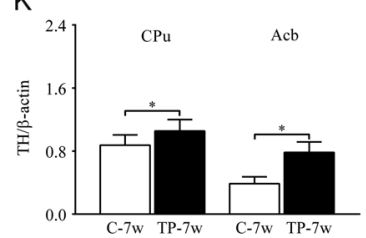

$\mathrm{N}$

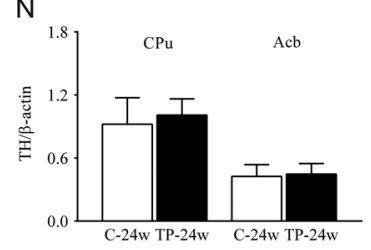

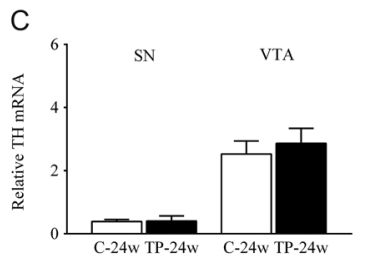
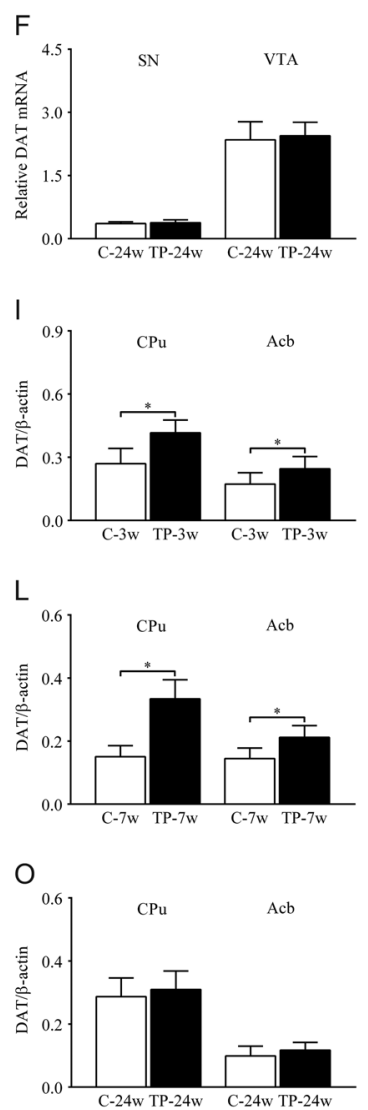

Figure 3

Effects of early postnatal androgen exposure on the mesoDAergic system. Early postnatal TP exposure increased TH mRNA ( $A$ and $B$ ) and DAT mRNA ( $D$ and $E$ ) levels in the SN and VTA, as well as the expression of TH and DAT protein levels in the CPu and Acb of PND21 (G, H and I) and PND49 (J, K and $\mathrm{L}$ ) male rats. ( $\mathrm{M}, \mathrm{N}$ and O) $=$ PND168. The results were expressed as mean \pm s.D. $(n=12) .{ }^{*} P<0.01$. levels in the CPu and Acb of TP-treated rats at PND21 and PND49, as well as the reduction in the DOPAC+HVA/DA ratio in the Acb of TP-treated rats at PND21. It was suggested that early postnatal androgen exposure induced the alteration of the mesoDAergic system in developing male rats. Androgen has been shown to influence DAergic system (Thiblin et al. 1999, Kindlundh et al. 2002, de Souza Silva et al. 2009). Anabolic androgenic steroids increase DAT density (Kindlundh et al. 2002) as well as DAergic metabolism (Thiblin et al. 1999) in the striatum of male rats. The administration of testosterone to castrated male rats prevents the castration-induced reduction of striatal TH activity (Abreu et al. 1988) and enhances DAergic activity in the neostriatum and Acb of male adult rats (de Souza Silva et al. 2009). In the present study, we found that early postnatal exposure to high levels of TP facilitated the activity of the mesoDAergic system and upregulated the expression of $\mathrm{TH}$ and DAT at mRNA and protein levels in PND21 and PND49 male rats. Furthermore, early postnatal TP exposure might increase the expression of vesicular monoamine transporters 2 (VMAT2). It was found in the previous study that TP supplements elevated VMAT2 levels in aged male rats (Wang et al. 2016). VMAT2 transports DA from the cytoplasm into synaptic storage vesicles to prevent DA from being metabolized. Thus, the increased DA content with reduction or without change in the DOPAC+HVA/DA ratio indicated there was more DA present in synaptic vesicles of DAergic neurons in TP-treated PND21 and PND49 rats. Enhanced mesoDAergic activity by early postnatal exposure to excessive testosterone might underlie the PND21 and PND49 behavioral deficits of early postnatal TP-exposed male rats.

The DAergic neurons in the SN and VTA are the sources of the nigrostriatal and mesocorticolimbic DAergic projections, respectively. They form the nigrostriatal and mesocorticolimbic circuits and regulate the function of 
A
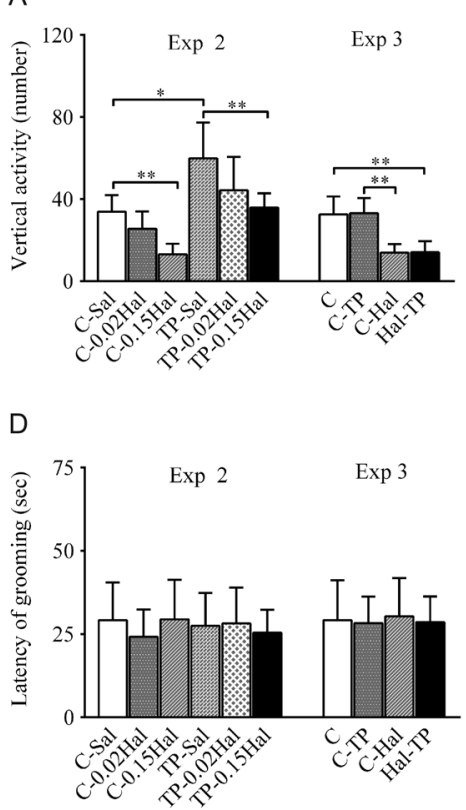

B

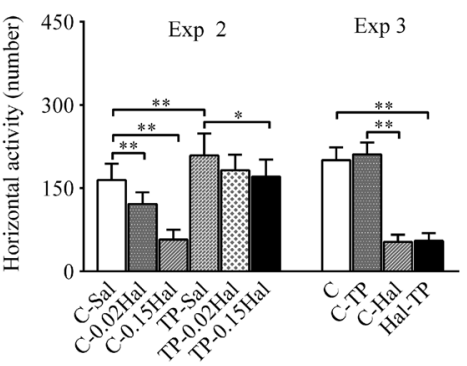

E

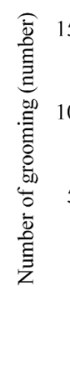

C

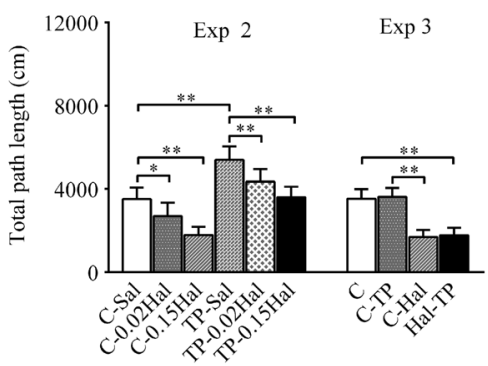

F

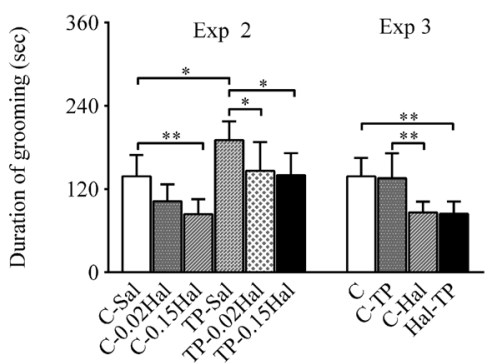

Figure 4

Effects of Hal on early postnatal TP exposure-induced behavioral defects in experiment (Exp) 2 and effects of Hal treatment concurrent with TP treatment on the neurobehaviors of developing male rats in Exp 3. Administration of Hal significantly ameliorated the early postnatal TP exposureinduced defects in motor (A, B and C) and grooming (D, E and F) behaviors of PND21 male rats (Exp 2). There was no significant difference in motor behavior and grooming behavior of PND21 male rats between C and C-TP, as well as C-Hal and Hal-TP (Exp 3). The results were expressed as mean \pm s.D. $(n=7) . * P<0.05, * * P<0.01$.

the basal ganglia (Blandini et al. 2000, Mehler-Wex et al. 2006), the subcortical structures that are considered to be of central relevance in the pathophysiology of TS (Peterson et al. 1993, Singer et al. 1993, Bronfeld \& BarGad 2013). It is known that the basal ganglia play an important role in motor control including simple and complex motor functions, such as grooming behavior in rodent. Grooming behavior is natural and ubiquitous. It consists of complex strings of movements. Due to its complex repetitive nature, rodent grooming behavior is a logical phenotype to be observed in putative models of TS (Berridge et al. 2005). Dopamine, a major modulator in the mesoDAergic systems, is involved in the regulation of motor and grooming behaviors in rodents (Hidaka et al. 2010, Taylor et al. 2010, Kalueff et al. 2016). The activation of central DAergic system markedly increases locomotor activity (Hidaka et al. 2010) as well as grooming behavior (Taylor et al. 2010) of rats. The increased locomotor activity and grooming behavior can be suppressed by Hal treatments (Hidaka et al. 2010, Taylor et al. 2010). Haloperidol, a formally approved medication in the United States (Egolf \& Coffey 2014), is used to treat behavioral disorders and hyperactivity (Tyler et al. 2017) and to control the tics and vocal utterances associated with TS (Termine et al. 2013, Tyler et al. 2017). It is a high-affinity antagonist of dopamine D2 receptors (Kapur \& Mamo 2003) and one of the most effective anti-DAergic agents for the reduction of tics (Silay \& Jankovic 2005, Scahill et al. 2006). In the present study, we found that Hal treatment to PND21 and PND49 male rats ameliorated the motor behavioral and grooming behavioral deficits induced by early postnatal TP exposure. Previous study revealed that Hal treatment prevented male hamsters from displaying conditioned place preference to vaginal secretions, which is dependent on testosterone levels (Bell \& Sisk 2013). It has been reported that conditioned place preference induced by testosterone can be blocked by dopamine receptor antagonist (Schroeder \& Packard 2000). Thus, the amelioratory effects of Hal on the defects of motor behavior and grooming behavior in our study suggested that the mesoDAergic system might be the targets through which early postnatal TP exposure induced the behavioral impairments of PND21 and PND49 male rats.

During the early postnatal development, high levels of testosterone exist in males compared with females (Slob et al. 1980, Baum et al. 1998). These high testosterone levels contribute to the organizational effects of androgen on the sexual dimorphic brain regions (Arnold \& Breedlove 1985) as well as the reproduction and energy homeostasis (Nohara 
A
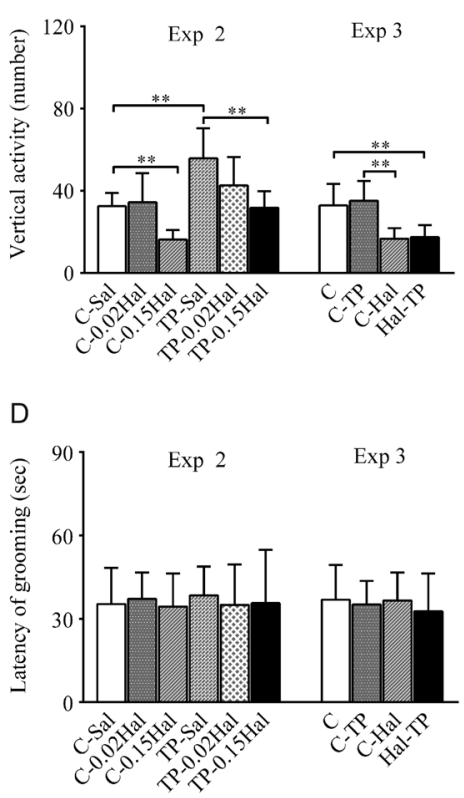

B

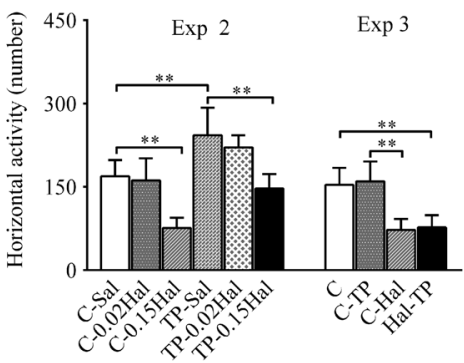

E

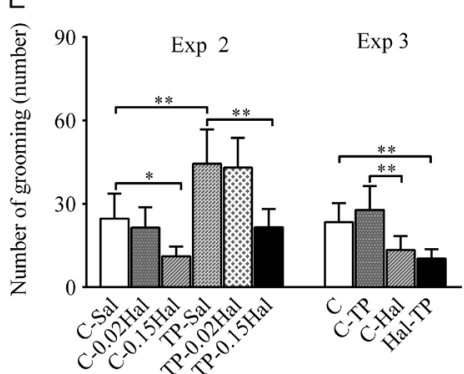

C

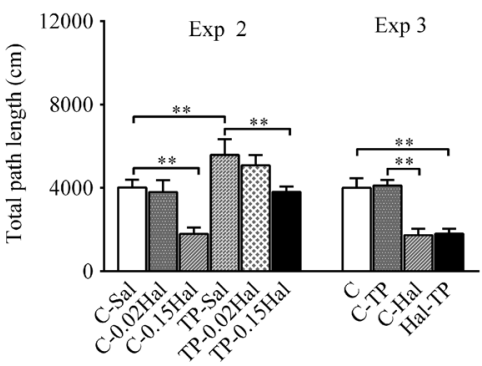

F

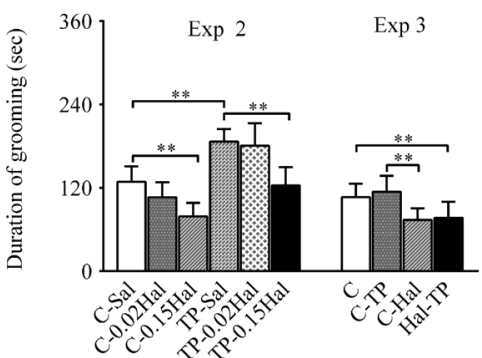

\section{Figure 5}

Effects of Hal on early postnatal TP exposure-induced behavioral defects in Exp 2 and effects of Hal treatment concurrent with TP treatment on the neurobehaviors of developing male rats in Exp 3. Administration of Hal significantly ameliorated the early postnatal TP exposure-induced defects in motor (A, B and C) and grooming (D, E and F) behaviors of PND49 male rats (Exp 2). There was no significant difference in motor behavior and grooming behavior of PND49 male rats between C and C-TP, as well as C-Hal and Hal-TP (Exp 3). The results were expressed as mean \pm s.D. $(n=7)$. *P<0.05, $* * P<0.01$.

et al. 2013). Administration of exogenous androgen after the critical periods of developing nervous system does not produces the enduring changes in behaviors (Diaz et al. 1995), which shows the activational effects of androgen on developing nervous system. In the present study, we found that early postnatal TP exposure enhanced the activity of the mesoDAergic system in PND21 male rats, and moreover, the enhanced mesoDAergic activity was still maintained in PND49 male rats although at this time PND49 male rats had much low serum testosterone levels due to the feedback inhibition of early postnatal TP exposure on testis development (low serum testosterone levels and light testis weight). When they were adults, the elevated mesoDAergic activity in the rats of the same treatment group was restored to the control level. The activational effects of androgen might explain the restoration of the mesoDAergic activity as well as behavioral parameters in the early postnatal TP-treated adult male rats. Testosterone propionate exposure to male pup rats started at PND7 in the present study. It has been found that injection of TP or androgen receptor antagonist (flutamide) to pup rats at this time does not induce the enduring changes of behavior (Diaz et al. 1995, Yamada et al. 2015).

Testosterone is known to mediate its effects by two different pathways of action, classical pathway of cytosolic/nuclear androgen receptors and non-classical pathway of membrane-associated androgen receptors (Deng et al. 2017). The classical effects of testosterone occur slowly because of the translation of newly synthesized proteins and the non-classical effects of testosterone occur fast due to the rapid phosphorylation of signal molecules (Deng et al. 2017). In Experiment 3 of the present study, we did not find the differences of motor behavior and grooming behavior between the rats receiving $\mathrm{Hal}$ treatment and the rats receiving Hal concurrent with TP treatment. Combining the results of no behavioral difference between $\mathrm{C}$ rats and C-TP rats, it seemed that TP treatment 30 min prior to open field test did not work via non-classical pathway of androgen receptors, which is worthwhile being investigated in the future.

The subcutaneous injection of TP at the dose of $0.5 \mathrm{mg}$ was adopted based on the previous study (Rhees et al. 1990). In the present study, 2-week TP treatment to PND7 male pup rats at this dose did not produce the alterations of body weight from 3-week old to adult. However, it created hyperandrogen milieu to early postnatal male pup rats, which resulted in the increased seminal vesicle weight and extremely high serum testosterone concentrations at 3-week old, low serum testosterone concentrations at 7-week old and lighter testes at both ages. The behavioral 
deficits and the enhanced mesoDAergic activity in early TP-treated rats were induced under the early postnatal hyperandrogen milieu, which presented the concerns of the undetermined physiological relevance of this testosterone effects. Therefore, to evaluate the physiological relevance of this testosterone effect, it is necessary in the future study to determine whether injection of TP at low dose or implantation of testosterone capsules could produce the similar effects on early postnatal male pup rats.

In addition to DA, early postnatal TP exposure induced the alteration of 5-HT levels in the Acb of PND 21 and PND49 male rats. The central serotonergic system innervates most of the brain regions and controls affection, cognition and movement along with DAergic system (Steeves \& Fox 2008). Dysfunction of serotonergic system is found in TS patients (Heinz et al. 1998, MüllerVahl et al. 2005, Behen et al. 2007), such as the abnormality of tryptophan metabolism (Behen et al. 2007) and the reduced availability of serotonin transporter (Heinz et al. 1998, Müller-Vahl et al. 2005). Therefore, how much extent the central serotoinergic system was influenced by early postnatal androgen exposure deserves further investigation in the future.

In conclusion, hyperandrogen environment during the early postnatal development induced the hyperactive motor as well as grooming behaviors and enhanced the activity of the mesoDAergic system of developing male rats. Dopamine D2 antagonist, haloperidol, could ameliorate the motor behavioral and grooming behavioral deficits induced by hyperandrogen environment. It is suggested that abnormal increments of testosterone levels during the early postnatal development might be a potential risk factor for the incidence of some male-based childhoodonset neuropsychiatric disorders through modulation of the mesoDAergic system.

\section{Declaration of interest}

The authors declare that there is no conflict of interest that could be perceived as prejudicing the impartiality of the research reported.

\section{Funding}

This work was supported in part by the Natural Science Foundation of China (No. 31240033) and the Natural Science Foundation of Hebei Province of China (No. C2012206033, No. C2017206072).

\section{Author contribution statement}

Q C, J X and Z G performed PCR, Western blot experiments, analyzed the data and wrote the manuscript. K Y performed LC-MS/MS assay and contributed to drafting. $\mathrm{H} Y$ and $\mathrm{C} R$ carried out behavioral experiments and the measurement of serum testosterone levels. $\mathrm{L} \mathrm{S}$ and $\mathrm{CH}$ interpreted data and revised the manuscript. S G designed the study, analyzed the data and revised the manuscript. All authors have read and approved the final version of the manuscript.

\section{References}

Abreu P, Hernandez G, Calzadilla CH \& Alonso R 1988 Reproductive hormones control striatal tyrosine hydroxylase activity in the male rat. Neuroscience Letters 95 213-217. (https://doi.org/10.1016/03043940(88)90659-3)

Adler A, Vescovo P, Robinson JK \& Kritzer MF 1999 Gonadectomy in adult life increases tyrosine hydroxylase immunoreactivity in the prefrontal cortex and decreases open field activity in male rats. Neuroscience 89 939-954. (https://doi.org/10.1016/S03064522(98)00341-8)

Albin RL, Koeppe RA, Bohnen NI, Nichols TE, Meyer P, Wernette K, Minoshima S, Kilbourn MR \& Frey KA 2003 Increased ventral striatal monoaminergic innervation in Tourette syndrome. Neurology $\mathbf{6 1}$ 310-315. (https://doi.org/10.1212/01.WNL.0000076181.39162.FC)

Arnold AP \& Breedlove SM 1985 Organizational and activational effects of sex steroids on brain and behavior: a reanalysis. Hormones and Behavior 19 469-498. (https://doi.org/10.1016/0018506X(85)90042-X)

Baum MJ, Brand T, Ooms M, Vreeburg JT \& Slob AK 1998 Immediate postnatal rise in whole body androgen content in male rats: correlation with increased testicular content and reduced body clearance of testosterone. Biology of Reproduction 38 980-986. (https:// doi.org/10.1095/biolreprod38.5.980)

Behen M, Chugani HT, Juhász C, Helder E, Ho A, Maqbool M, Rothermel RD, Perry J \& Muzik O 2007 Abnormal brain tryptophan metabolism and clinical correlates in Tourette syndrome. Movement Disorders 22 2256-2262. (https://doi.org/10.1002/mds.21712)

Bell MR \& Sisk CL 2013 Dopamine mediates testosterone-induced social reward in male Syrian hamsters. Endocrinology 154 1225-1234. (https://doi.org/10.1210/en.2012-2042)

Berridge KC, Aldridge JW, Houchard KR \& Zhuang X 2005 Sequential superstereotypy of an instinctive fixed action pattern in hyper-dopaminergic mutant mice: a model of obsessive compulsive disorder and Tourette's. BMC Biology 3 4. (https://doi.org/10.1186/1741-7007-3-4)

Blandini F, Nappi G, Tassorelli C \& Martignoni E 2000 Functional changes of the basal ganglia circuitry in Parkinson's disease. Progress in Neurobiology 62 63-88. (https://doi.org/10.1016/S03010082(99)00067-2)

Bloch MH \& Leckman JF 2009 Clinical course of Tourette syndrome. Journal of Psychosomatic Research 67 497-501. (https://doi. org/10.1016/j.jpsychores.2009.09.002)

Bortolato M, Muroni A \& Marrous F 2007 Treatment of Tourette's syndrome with Finasteride. American Journal of Psychiatry 164 1914-1915. (https://doi.org/10.1176/appi.ajp.2007.07060978)

Bronfeld M \& Bar-Gad I 2013 Tic disorders: what happens in the basal ganglia? Neuroscientist 19 101-108. (https://doi. org/10.1177/1073858412444466)

Celec P, Ostatníková D \& Hodosy J 2015 On the effects of testosterone on brain behavioral functions. Frontiers in Neuroscience 9 12. (https://doi. org/10.3389/fnins.2015.00012)

Chen JY, Wang EA, Cepeda C \& Levine MS 2013 Dopamine imbalance in Huntington's disease: a mechanism for the lack of behavioral flexibility. Frontiers in Neuroscience 7 114. (https://doi.org/10.3389/ fnins.2013.00114)

Cui R, Zhang G, Kang Y, Cheng Q, Tan H, Cui H \& Shi G 2012 Amelioratory effects of testosterone propionate supplement on behavioral, biochemical and morphological parameters in aged rats. Experimental Gerontology 47 67-76. (https://doi.org/10.1016/j. exger.2011.10.009) 
de Souza Silva MA, Mattern C, Topic B, Buddenberg TE \& Huston JP 2009 Dopaminergic and serotonergic activity in neostriatum and nucleus accumbens enhanced by intranasal administration of testosterone. European Neuropsychopharmacology 19 53-63. (https:// doi.org/10.1016/j.euroneuro.2008.08.003)

Deng Q, Zhang Z, Wu Y, Yu WY, Zhang J, Jiang ZM, Zhang Y, Liang H \& Gui YT 2017 Non-genomic action of androgens is mediated by rapid phosphorylation and regulation of androgen receptor trafficking. Cellular Physiology and Biochemistry 43 223-236. (https://doi. org/10.1159/000480343)

Diaz DR, Fleming DE \& Rhees RW 1995 The hormone-sensitive early postnatal periods for sexual differentiation of feminine behavior and luteinizing hormone secretion in male and female rats. Developmental Brain Research 86 227-232. (https://doi.org/10.1016/01653806(95)00029-D)

Egolf A \& Coffey BJ 2014 Current pharmacotherapeutic approaches for the treatment of Tourette syndrome. Drugs Today 50 159-179. (https://doi.org/10.1358/dot.2014.50.2.2097801)

Freeman RD, Fast DK, Burd L, Kerbeshian J, Robertson MM \& Sandor P 2000 An international perspective on Tourette syndrome: selected findings from 3,500 individuals in 22 countries. Developmental Medicine and Child Neurology 42 436-447. (https://doi. org/10.1111/j.1469-8749.2000.tb00346.x)

Frye CA, Edinger K \& Sumida K 2008 Androgen administration to aged male mice increases anti-anxiety behavior and enhances cognitive performance. Neuropsychopharmacology 33 1049-1061. (https://doi. org/10.1038/sj.npp.1301498)

Heinz A, Knable MB, Wolf SS, Jones DW, Gorey JG, Hyde TM \& Weinberger DR 1998 Tourette's syndrome: [I-123]beta-CIT SPECT correlates of vocal tic severity. Neurology $\mathbf{5 1}$ 1069-1074. (https://doi. org/10.1212/WNL.51.4.1069)

Hidaka N, Suemaru K \& Araki H 2010 Serotonin-dopamine antagonism ameliorates impairments of spontaneous alternation and locomotor hyperactivity induced by repeated electroconvulsive seizures in rats. Epilepsy Research 90 221-227. (https://doi.org/10.1016/j. eplepsyres.2010.05.004)

Howes OD \& Kapur S 2009 The dopamine hypothesis of schizophrenia: version III - the final common pathway. Schizophrenia Bulletin 35 549-562. (https://doi.org/10.1093/schbul/sbp006)

Jin R, Zheng RY, Huang WW, Xu HQ, Shao B, Chen H \& Feng L 2005 Epidemiological survey of Tourette syndrome in children and adolescents in Wenzhou of P.R. China. European Journal Epidemiology 20 925-927. (https://doi.org/10.1007/s10654-005-2953-z)

Kalueff AV, Stewart AM, Song C, Berridge KC, Graybiel AM \& Fentress JC 2016 Neurobiology of rodent self-grooming and its value for translational neuroscience. Nature Reviews Neuroscience 17 45-59. (https://doi.org/10.1038/nrn.2015.8)

Kapur S \& Mamo D 2003 Half a century of antipsychotics and still a central role for dopamine D2 receptors. Progress in NeuroPsychopharmacology and Biological Psychiatry 27 1081-1090. (https:// doi.org/10.1016/j.pnpbp.2003.09.004)

Kegeles LS, Abi-Dargham A, Frankle WG, Gil R, Cooper TB, Slifstein M, Hwang DR, Huang Y, Haber SN \& Laruelle M 2010 Increased synaptic dopamine function in associative regions of the striatum in schizophrenia. Archives of General Psychiatry 67 231-239. (https://doi. org/10.1001/archgenpsychiatry.2010.10)

Khalifa N \& von Knorring AL 2003 Prevalence of tic disorders and Tourette syndrome in a Swedish school population. Developmental Medicine and Child Neurology 45 315-319. (https://doi. org/10.1111/j.1469-8749.2003.tb00402.x)

Kindlundh AM, Bergstrom M, Monazzam A, Hallberg M, Blomqvist G, Langstrom B \& Nyberg F 2002 Dopaminergic effects after chronic treatment with nandrolone visualized in rat brain by positron emission tomography. Progress in Neuro-Psychopharmacology and Biological Psychiatry 26 1303-1308. (https://doi.org/10.1016/S02785846(02)00293-2)
Leckman JF \& Scahill L 1990 Possible exacerbation of tics by androgenic steroids. New England Journal of Medicine 3221674

Leckman JF, Bloch MH, Smith ME, Larabi D \& Hampson M 2010 Neurobiological substrates of Tourette's disorder. Journal of Child and Adolescent Psychopharmacology 20 237-247. (https://doi.org/10.1089/ cap.2009.0118)

Mehler-Wex C, Riederer P \& Gerlach M 2006 Dopaminergic dysbalance in distinct basal ganglia neurocircuits: implications for the pathophysiology of Parkinson's disease, schizophrenia and attention deficit hyperactivity disorder. Neurotoxicity Research 10 167-179. (https://doi.org/10.1007/BF03033354)

Müller-Vahl KR, Meyer GJ, Knapp WH, Emrich HM, Gielow P, Brücke T \& Berding G 2005 Serotonin transporter binding in Tourette Syndrome. Neuroscience Letters 385 120-125. (https://doi.org/10.1016/j. neulet.2005.05.031)

Muroni A, Paba S, Puligheddu M, Marrosu F \& Bortolato M 2011 A preliminary study of finasteride in Tourette syndrome. Movement Disorders 26 2146-2147. (https://doi.org/10.1002/mds.23810)

Nohara K, Liu S, Meyers MS, Waget A, Ferron M, Karsenty G, Burcelin R \& Mauvais-Jarvis F 2013 Developmental androgen excess disrupts reproduction and energy homeostasis in adult male mice. Journal of Endocrinology 219 259-268. (https://doi.org/10.1530/JOE-13-0230)

Paxinos G \& Watson C 1997 The Rat Brain in Stereotaxic Coordinates. San Diego/London: Academic Press.

Peterson B, Riddle MA, Cohen DJ, Katz LD, Smith JC, Hardin MT \& Leckman JF 1993 Reduced basal ganglia volumes in Tourette's syndrome using three dimensional reconstruction techniques from magnetic resonance images. Neurology 43 941-949. (https://doi. org/10.1212/WNL.43.5.941)

Peterson BS, Zhang H, Anderson GM \& Leckman JF 1998 A double blind, placebo-controlled, crossover trial of an antiandrogen in the treatment of Tourette's syndrome. Journal of Clinical Psychopharmacology 18 324-331. (https://doi.org/10.1097/00004714199808000-00013)

Rhees RW, Shryne JE \& Gorski RA 1990 Termination of the hormonesensitive period for differentiation of the sexually dimorphic nucleus of the preoptic area in male and female rats. Developmental Brain Research 52 17-23. (https://doi.org/10.1016/0165-3806(90)90217-M)

Sandyk R, Bamford CR \& Iacono RP 1988 Sexual hormones in the pathophysiology of Tourette's syndrome. International Journal of Neuroscience 38 125-129. (https://doi. org/10.3109/00207458809000490)

Scahill L, Erenberg G, Berlin CM Jr, Budman C, Coffey BJ, Jankovic J, Kiessling L, King RA, Kurlan R, Lang A, et al. 2006 Contemporary assessment and pharmacotherapy of tourette syndrome. NeuroRx $\mathbf{3}$ 192-206. (https://doi.org/10.1016/j.nurx.2006.01.009)

Schroeder JP \& Packard MG 2000 Role of dopamine receptor subtypes in the acquisition of a testosterone conditioned place preference in rats. Neuroscience Letters 282 17-20. (https://doi.org/10.1016/S03043940(00)00839-9)

Silay YS \& Jankovic J 2005 Emerging drugs in Tourette syndrome. Expert Opinion on Emerging Drugs 10 365-380. (https://doi. org/10.1517/14728214.10.2.365)

Singer HS, Hahn IH \& Moran TH 1991 Abnormal dopamine uptake sites in postmortem striatum from patients with Tourette's syndrome. Annals of Neurology 30 558-562. (https://doi.org/10.1002/ ana.410300408)

Singer HS, Reiss AL, Brown JE, Aylward EH, Shih B, Chee E, Harris EL, Reader MJ, Chase GA, Bryan RN, et al. 1993 Volumetric MRI changes in basal ganglia of children with Tourette's syndrome. Neurology $\mathbf{4 3}$ 950-956. (https://doi.org/10.1212/WNL.43.5.950)

Singer HS, Szymanski S, Giuliano J, Yokoi F, Dogan AS, Brasic JR, Zhou Y, Grace AA \& Wong DF 2002 Elevated intrasynaptic dopamine release in Tourette's syndrome measured by PET. American Journal of Psychiatry 159 1329-1336. (https://doi.org/10.1176/appi. ajp.159.8.1329) 
Slob AK, Ooms MP \& Vreeburg JT 1980 Prenatal and early postnatal sex differences in plasma and gonadal testosterone and plasma luteinizing hormone in female and male rats. Journal of Endocrinology 87 81-87. (https://doi.org/10.1677/joe.0.0870081)

Steeves TD \& Fox SH 2008 Neurobiological basis of serotonin-dopamine antagonists in the treatment of Gilles de la Tourette syndrome. Progress in Brain Research 172 495-513. (https://doi.org/10.1016/ S0079-6123(08)00924-2)

Taylor JL, Rajbhandari AK, Berridge KC \& Aldridge JW 2010 Dopamine receptor modulation of repetitive grooming actions in the rat: potential relevance for Tourette syndrome. Brain Research 1322 92-101. (https://doi.org/10.1016/j.brainres.2010.01.052)

Termine C, Selvini C, Rossi G \& Balottin U 2013 Emerging treatment strategies in Tourette syndrome: what's in the pipeline? International Review of Neurobiology 112 445-480. (https://doi.org/10.1016/B978-012-411546-0.00015-9)

Thiblin I, Finn A, Ross SB \& Stenfors C 1999 Increased dopaminergic and 5-hydroxytryptaminergic activities in male rat brain following long-term treatment with anabolic androgenic steroids. British Journal of Pharmacology 126 1301-1306. (https://doi.org/10.1038/ sj.bjp.0702412)

Tyler MW, Zaldivar-Diez J \& Haggarty SJ 2017 Classics in chemical neuroscience: haloperidol. ACS Chemical Neuroscience 8 444-453. (https://doi.org/10.1021/acschemneuro.7b00018)
Wang L, Kang Y, Zhang G, Zhang Y, Cui R, Yan W, Tan H, Li S, Wu B, Cui H, et al. 2016 Deficits in coordinated motor behavior and in nigrostriatal dopaminergic system ameliorated and VMAT2 expression up-regulated in aged male rats by administration of testosterone propionate. Experimental Gerontology 78 1-11. (https:// doi.org/10.1016/j.exger.2016.03.003)

Wong DF, Brasić JR, Singer HS, Schretlen DJ, Kuwabara H, Zhou Y, Nandi A, Maris MA, Alexander M, Ye W, et al. 2008 Mechanisms of dopaminergic and serotonergic neurotransmission in Tourette syndrome: clues from an in vivo neurochemistry study with PET. Neuropsychopharmacology 33 1239-1251. (https://doi.org/10.1038/ sj.npp.1301528)

Yamada S, Ohoya M, Takanami K, Matsuda KI \& Kawata M 2015 Critical role of androgen receptor in the postnatal period in male sexual behavior in rats. Neuroscience Letters 609 189-193. (https://doi. org/10.1016/j.neulet.2015.10.040)

Zhang G, Shi G, Tan H, Kang Y \& Cui H 2011 Intranasal administration of testosterone increased immobile-sniffing, exploratory behavior, motor behavior and grooming behavior in rats. Hormones and Behavior 59 477-483. (https://doi.org/10.1016/j.yhbeh.2011.01.007)

Zou LP, Wang Y, Zhang LP, Zhao JB, Lu JF, Liu Q \& Wang HY 2011 Tourette syndrome and excitatory substances: is there a connection? Child's Nervous System 27 793-802. (https://doi.org/10.1007/s00381010-1318-4)

Received in final form 17 March 2018

Accepted 21 March 2018

Accepted Preprint published online 21 March 2018
(C) 2018 Society for Endocrinology Published by Bioscientifica Ltd.
Printed in Great Britain 